

\section{AUSTRALAN JOURNAL OF ELECTRICAL \& ELECTRONICS ENGINEERING \\ Vol 2, No 3}

\section{CONTENTS}

\section{conference papers}

167. Load capability and collapse margin analysis of the large scale Díeensiland poter system

\section{G Alumuller \& TK Sahia}

175. Conchation beituen time and frequengy domain polarisation measurements for transformer moisture assessment

\section{TK Saha, R Middlaton \& A Thomas}

183. Decentralised source scheduling in a model nanogrid using DC bus signalling:

\section{J Schönfferger, R Duke \& S Round}

191. Recogitition of partial discharge wavestrape patterns for gas insulated switchigear

\section{CS Chang, KH Loe \& C Cheaning}

199. Monte Carlo simulation and its application in modelling

electricity market behaviour

I Rose, DR Bones \& II Pimentel

209. Modelling of saturation and cross-saturation effeets in an interior PM automotive allernator

\section{V Životic-Kukol), WLL Soong \& NI Ertugrul}

217. Monitoring of individual modal damping changes in multi-modal power systems

RA Wilkshire, P O'Shea \& G Ledwich
223. Analysis of a series inductance implementation on a thregphase shunt active power filter for various types of nonlinear loais

\section{HH Tumbelaka, LJ Borle \& GV Nayar}

233. Harmonic quality of multilevel cascadid inverters with random carrier phase pulse with modulation PC Sernia \& GR Walker

239. Transmission planning in competitive power markets Bonsidering the uncertainties in market operation

\section{GBS Shriestha \& PAJ Fonseka}

247. An investigation of battery voltage equalisation topologies for an electric vehichle

\section{M-KL Hsieh, S Round \& R Duke}

255. Maximizing static voltage stability margin in power systems using a new generation pattern A Sode-Yome \& N Mithulananthan

263. System dynamics modelling: application to slectricity transmission netwark asset management

\section{J Grisp \& D Birtuhistle}

273. Energy ingetetion by distributed generation for enhaneement of voltegige profile in SWER systems

MA Kasham \& G Ledwich 


\section{GUEST EDITORS}

EDITORIAL

PANEL

\section{BOARD MEMBERS ELECTRICAL COLEGE}

\section{CORRESPONDING MEMBERS}

\section{JOURNALS COORDINATOR}

Richard Dixon-Hughes John Green Paul Edwards

\section{Akhtar Kalam}

Tapan Saha

Pa

Amal Hanna - Chairman

Liam Waldron - Deputy Chairman

Pat Pearl - Immediate Past Chairman

Merv Green

Albert Koenig

Greg Skinner

Peter Tromans

Ljubo Vlacic

Roger Franzen

David Edwards

Bill Pickering

Brian Knight

Karyne Wong

Michael Evans

Mark Blundell

Eric Goddard

Martine Griffiths - Committee Administrator

\section{BOARD MEMBERS ITEE COLEGE}

\author{
David Edwards - Chairman \\ Adrian Smith - \\ Immediate Past Chairman \\ John Gordon \\ Abdulkadir Sajeev \\ Jeffrey Walsh \\ Brian O'Neill \\ Richard Dixon-Hughes \\ Michael Kyriacou \\ Bill Pickering \\ Harry Wragge \\ Amal Hanna \\ Frank Novacco \\ Geoff Sizer \\ Christine Haydon \\ Robin King \\ Paul Edwards \\ Martine Griffiths - \\ Committee Administrator
}

$K$ Davis

R P Ellen

$J$ Hyne

\author{
Elizabeth Cooper \\ ecooper@engineersmedia.com.au
}

PRODUCTION

Jin Liaskos

\section{EDITORIAL POLICY}

The policy of the publishers of the Australian Journal of Electrical and Electronics Engineering is to publish a variety of contributions to the science and practice of electrical engineering. Major fields of interest include electronics and communications engineering, electric energy, automation, control and instrumentation, computer and information technology. The Australian Journal of Electrical and Electronics Engineering aims to publish reviewed technical papers in the major fields of interest, as well as in allied fields.

Papers should be related to the relevant field and will usually fall into one of the following categories:
a. Research paper.
A paper making an original contribution to engineering knowledge.
b. Special interest paper.
Report on significant asspects of a major or notable project.
c. Review paper for specialists.
An overview of a relevant area intended for specialists in the field covered.
d. Review paper for non-specialists.
An overview of a relevant area suitable for a reader with an electrical/electronics background.
e. Tutorial paper.
A paper which explains an important subject or clarifies the approach to an area of design or investigation.
f. Technical note.
A technical note, or a letter to the Editors which is not sufficiently developed or extensive in scope to constitute a full paper.
g. A contribution to discuss a published paper to which the original author's response will be sought.

From time to time invitations are presented to particular authors to write a paper for the Journal. This most usually occurs when it is decided to collect a number of papers relating to one subject into a given issue, often with a guest editor.

The expected length of acceptable contributions will vary considerably but 4000 to 5000 words or equivalent for papers would be the norm. Technical notes should not exceed 1500 words and contributions to discuss published papers should not exceed 500 words. 


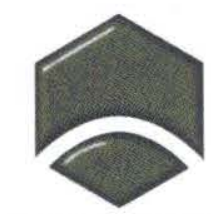

ENGINEERS

AUSTRALIA

\section{ELECTRICAL \& ELECTRONICS ENGINEERING}

Published by:

Engineers Media

PO Box 588,

Crows Nest NSW 1585

Ph: (02) 94381533

website: http://www.engineersmedia.com.au

for Engineers Australia

\section{Subscription enquiries:}

Member Services

National Office

Engineers Australia

Ph: (02) 62706555

Non-member subscription requests to:

Engineers Media

PO Box 588

Crows Nest NSW 1585

Ph: (02) 94381533

\section{Single copies also available from:}

Engineers Media

\section{Cover photo:}

A Statomat RWE2/130 winding machine in the CMG P/L motor manufacturing facility in Melbourne's outer east, the only company in Australia to design and manufacture motors CMG P/L is the 2005 winner of the victorian Engineering Excellence Award for Innovation for its SpeedMaster(TM) Integral Motor-Drive.

Photograph courtesy CMG P/L

(C) The Institution of Engineers, Australia 2005. 


\section{foreword}

The Australasian Universities Power Engineering Conference (AUPEC) 2004 was held at the University of Queensland in Brisbane. The theme of the conference was "Challenges and opportunities in the deregulated power industry". Blackouts are becoming more frequent and causing substantial losses to consumers. There is a need for security in the modern complex and interconnected power system. New techniques and solutions are required to manage and operate the deregulated electricity industry in a market environment.

AUPEC 2004 received over 235 digests / full papers from 17 countries. The prospective authors were academics, research higher degree students and power industry professionals. After a thorough review process 167 papers were accepted for presentation and discussion. Now out of these 167 papers we have selected the top 15 papers for presentation in this special issue of the Journal of Electrical and Electronics Engineering. In 2005, the AUPEC 2005 will be hosted by the University of Tasmania in Hobart.

Akhtar Kalam Guest Editor

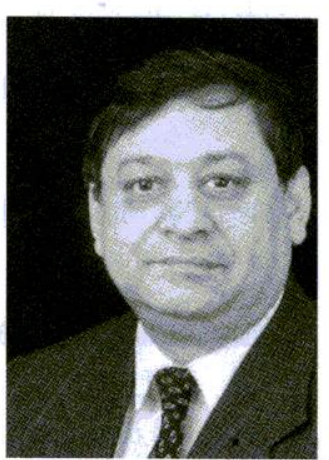

Tapan Saha Guest Editor

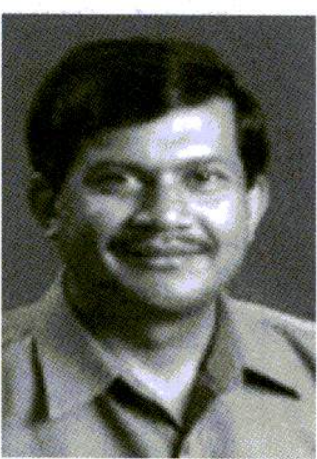




\section{ELECTRICAL \& ELECTRONICS ENGINALANEERING $\approx$}

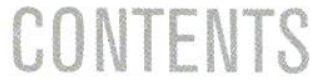

conference papers

167. Load capability and collapse margin analysis of the large scale Queensland power system C Aumuller \& TK Saha

175. Correlation between time and frequency domain polarisation measurements for transformer moisture assessment TK Saha, R Middleton \& A Thomas

183. Decentralised source scheduling in a model nanogrid using DC bus signalling J Schönberger, R Duke \& S Round

191. Recognition of partial discharge waveshape patterns for gas insulated switchgear CS Chang, KH Lee \& C Chang

199. Monte Carlo simulation and its application in modelling electricity market behaviour I Rose, DR Bones \& M Pimentel

209. Modelling of saturation and cross-saturation effects in an interior PM automotive alternator V Životić-Kukolj, WL Soong \& N Ertugrul

217. Monitoring of individual modal damping changes in multi-modal power systems RA Wiltshire, P O'Shea \& G Ledwich

223. Analysis of a series inductance implementation on a three-phase shunt active power filter for various types of non-linear loads HH Tumbelaka, LJ Borle \& CV Nayar

233. Harmonic quality of multilevel cascade inverters with random carrier phase pulse width modulation PC Sernia \& GR Walker

239. Transmission planning in competitive power markets considering the uncertainties in market operation GB Shrestha \& PAJ Fonseka

247. An investigation of battery voltage equalisation topologies for an electric vehicle M-KL Hsieh, S Round \& R Duke

255. Maximizing static voltage stability margin in power systems using a new generation pattern A Sode-Yome \& N Mithulananthan

263. System dynamics modelling: application to electricity transmission network asset management J Crisp \& D Birtwhistle

273. Energy injection by distributed generation for enhancement of voltage profile in SWER systems MA Kashem \& G Ledwich

Published by Engineers Media for Engineers Australia.

All correspondence, including manuscripts and advertising enquiries, should be addressed to Engineers Media, PO Box 588 , Crows Nest NSW 1585. Abstracting is permitted with due credit to the Australian Journal of Electrical \& Electronics Engineering. Reprints of technical articles are available. Quantities of not fewer than 25 may be ordered. 


\title{
Analysis of a series inductance implementation on a three-phase shunt active power filter for various types of non-linear loads *
}

\author{
HH Tumbelaka \\ Department of Electrical and Computer Engineering \\ Curtin University of Technology, Western Australia \\ LJ Borle \\ School of Electrical, Electronic and Computer Engineering \\ University of Western Australia, Western Australia \\ CV Nayar \\ Department of Electrical and Computer Engineering \\ Curtin University of Technology, Western Australia
}

\begin{abstract}
SUMMARY: In this paper, the implementation of a shunt active power filter with a small series inductor for a three-phase system is presented. The filter consists of a three-phase current-controlled voltage source inverter (CC-VSI) with a filter inductance at the ac output and a dc-bus capacitor. The series inductor is primarily used to handle the harmonic voltage source. The main concern is the size of the series inductance so that it is as small as possible but effective in compensating the harmonics. In order to select the proper value of the series inductance, the simulation is conducted to evaluate the value for different types of loads.
\end{abstract}

\section{INTRODUCTION}

Non-linear loads, especially power electronic loads, create harmonic currents and voltages in the power systems. In many cases, non-linear loads consist of combinations of harmonic voltage sources and harmonic current sources, and may contain significant load unbalance (ex. single phase loads on a three phase-system) that creates negative and zero sequence components.

For many years, various active power filters (APF) have been developed to suppress the harmonics, as well as to compensate for reactive power, so that the utility grid will supply sinusoidal voltage and current with unity power factor. ${ }^{1,2}$ Basically, the shunt type APF acts to eliminate the reactive and harmonic currents produced by non-linear loads from the grid current by injecting compensating currents intended to result in sinusoidal grid currents with unity power factor. This filter has been proven to be effective in compensating harmonic current sources, but it cannot properly compensate for harmonic voltage sources. With mixed non-linear loads, it has been proven that a modified three-phase line current forcing shunt APF combined with a series inductor installed at the Point of Common Coupling (PCC) is

* Paper presented at the Australasian Universities Power Engineering Conference, 2004 effective in compensating harmonic current sources, as well as harmonic voltage sources. ${ }^{3}$ The filter is able to handle the load unbalance as well. Figure 1 shows the filter configuration.

The addition of a small series inductance is simple, effective and practical not only to support the shunt APF to compensate the harmonic voltage source but also to improve the filtering process for other types of loads. However, the inductor size has to be selected properly, because it is related to the size of other filter components and to filtering characteristics. Therefore, in this paper, the selection and effectiveness of a series inductor are examined.

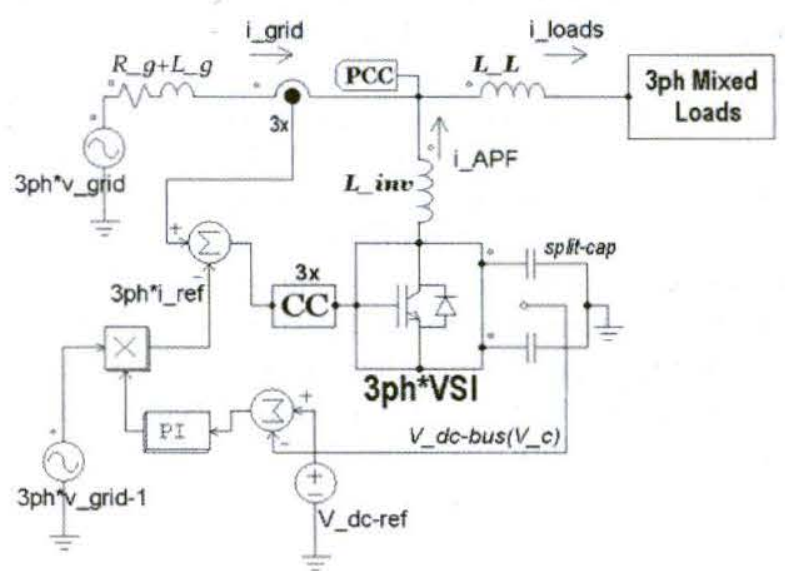

Figure 1: Active power filter configuration. 


\section{A THREE-PHASE SHUNT ACTIVE POWER FILTER OPERATION}

\subsection{Operation principle of a three-phase shunt active power filter}

The three-phase shunt active power filter is a fourwire three-phase current controlled voltage-source inverter (CC-VSI) with a mid-point earthed, split capacitor in the dc bus and inductors in the ac output (It is essentially three independent singlephase inverters with a common dc bus).

In this scheme (Figure 1), the CC-VSI is operated to directly control the ac grid current rather than its own current. The grid current is sensed and directly controlled to follow symmetrical sinusoidal reference signals in-phase with the grid voltage. Hence, by putting the current sensors on the grid side, the grid current is forced to behave as a sinusoidal current source and the grid appears as a high-impedance circuit for harmonics. By forcing the grid current to be sinusoidal, the APF automatically provides the harmonic, reactive, negative and zero sequence currents for the load, following the basic current summation rule:

$i_{\text {grid }}=i_{\text {APF }}+i_{\text {loads }}$

The sinusoidal grid current reference signal is given by:

$i_{\text {ref }}=k v_{\text {grid-l }}$

where $v_{\text {grid- }}$ is the fundamental component of the grid voltage, and $k$ is obtained from an outer control loop regulating the CC-VSI dc-bus voltage. This can be accomplished by a simple PI control loop. This is an effective way of determining the required magnitude of active current required, since any mismatch between the required load active current and that being forced by the CC-VSI would result in the necessary corrections to regulate the dc-bus voltage.

A key component of this system is the small-added series inductance $L_{L}$. Without this inductance, load harmonic voltage sources would produce harmonic currents through the grid impedance, which could not be compensated by a shunt APF. Currents from the APF do not significantly change the harmonic voltage at the loads. Therefore, there would still be harmonic voltages across the grid impedance, which would continue to produce harmonic currents. The inductance $L_{L}$ provides the required voltage decoupling between load harmonic voltage sources and the grid (Figure 2).

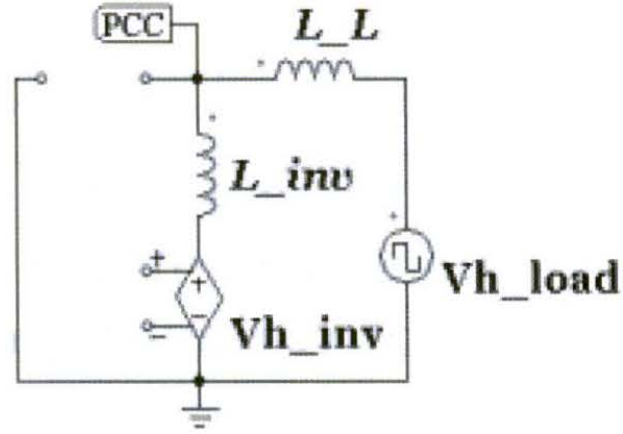

Figure 2: $\quad$ Equivalent circuit for low order harmonics.

\subsection{Current control loop}

The current control loop employs the ramptime current control technique. ${ }^{4}$ The principle operation of ramptime current control is based on the concept of zero average current error (ZACE) with a constant switching period (or frequency). In this application, the current error signal is the difference between the actual grid current and the desired/reference grid current waveform.

In this control loop, the output current (diAPF/dt) of the inverter through $L_{\text {inv }}$ (inverter output inductance) is expressed as

$\frac{d i_{A P F}}{d t}=-\frac{v_{P C C}}{L_{i n v}}+(2 s-1) \frac{v_{C}}{2 L_{i n v}}$

$s=1$ if the upper switch is closed, and $s=0$ if the upper switch is open. The switches are operated on a complementary basis. The voltage source inverter can always generate currents and the system is stable as long as $v_{C} / 2>V_{P C C \cdot p k}$. Hence, although $v_{C}$ (dc bus voltage) contains ripple, $v_{C}$ has to be sufficiently large so as to outweigh the fluctuation of $v_{P C C}$ (voltage at PCC) and small perturbations.

Full controllability is achieved when $d i_{A P F} / d t$ is greater than the di/dt of the loads. This provides the CC-VSI with complete control over the ac grid current. Therefore, equation (3) expresses the boundaries of controllability (pu), represented in Figure 3 for $V_{P C C-\mathrm{rms}}=1 \mathrm{pu}, V_{C-d c}=3.333 \mathrm{pu}, X_{i n v}=1 \%, f=50 \mathrm{~Hz}$ with $s=1$ (upper curve) and $s=0$ (lower curve). As long the $d i / d t$ of the loads is within the boundaries $\left(d i_{A P F}\right.$ / $d t)$, the current control will force the grid currents to track the reference signals perfectly. For this case, filter parameters must be chosen such that the di/dt of the loads never exceeds the upper and lower curves of the boundaries of controllability. 


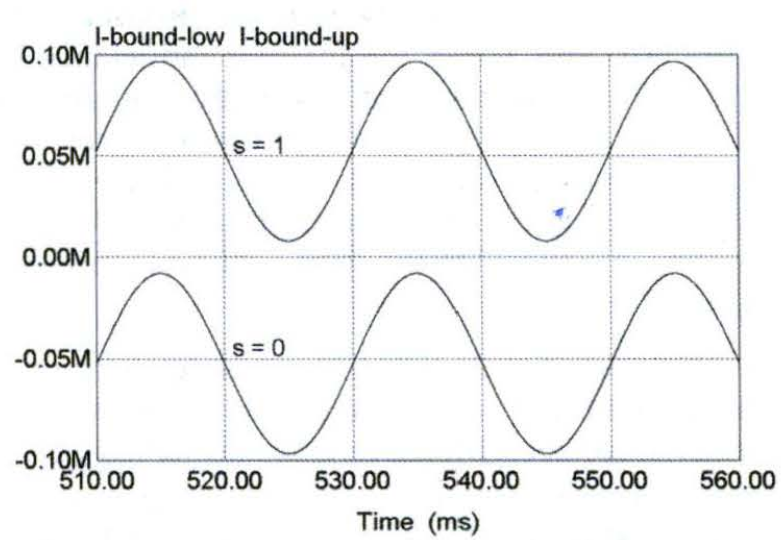

Figure 3: The boundaries of controllability $\left(d i_{A P F} / d t-p u\right)$ for $V_{P C C-r m s}=1 p u, V_{C \cdot d c}=$ $3.333 \mathrm{pu}, X_{i n v}=1 \%, f=50 \mathrm{~Hz}$.

\subsection{Voltage control loop}

The outer voltage control loop uses a PI controller to adjust the gain $k$ of the reference currents in order to regulate the desired dc bus voltage. The PI parameters, $K_{p}$ and $T_{i}$ must be determined so that the characteristic equation of the closed-loop transfer function has poles in the left-hand side of the s plane. $T_{i}$ is chosen such that the speed of response of the voltage control loop is much slower than that of the current control loop. Hence, the inner current and outer voltage control loops are decoupled.

\section{THE RELATIONSHIP BETWEEN A SERIES INDUCTANCE $L_{L}$ AND VARIOUS NON- LINEAR LOADS}

\subsection{Compensation for harmonic voltage sources}

To show a compensation for harmonic voltage sources, a simulation was conducted based on a three-phase ac system with a grid voltage rms value of $1 \mathrm{pu}\left(\mathrm{V}_{\text {base }}\right.$ phase-neutral $\left.=240 \mathrm{~V}_{\mathrm{rms}}\right), X_{\text {inv }}=1.96 \%, X_{\mathrm{g}}$ $=0.8 \%, X_{L}=0.8 \%$. The load is a three-phase diode rectifier with dc filter capacitor as a harmonic voltage source, with $\mathrm{I}_{\text {load-rms }}=1 \mathrm{pu}\left(\mathrm{I}_{\text {base }}=10 \mathrm{~A}_{\mathrm{rms}}\right)$. Computer simulation results are shown in Figures 4, 5 and 6.

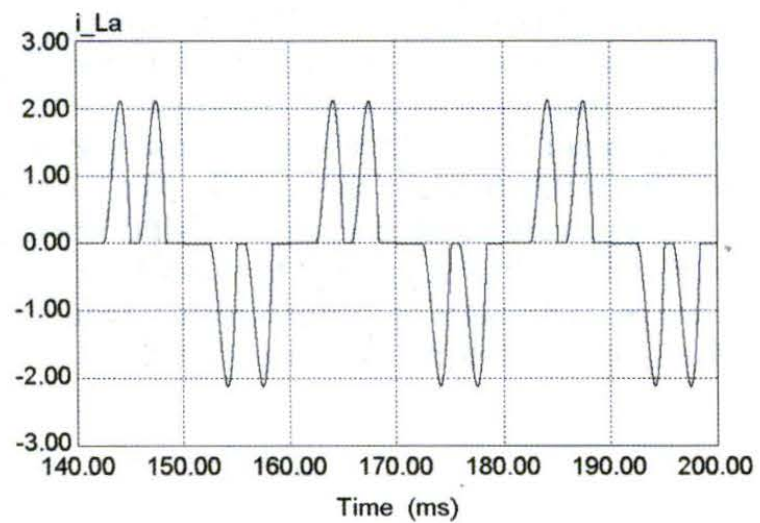

Figure 4: The load current (phase $\mathrm{A}-\mathrm{pu}$ ) for a three-phase harmonic voltage source.

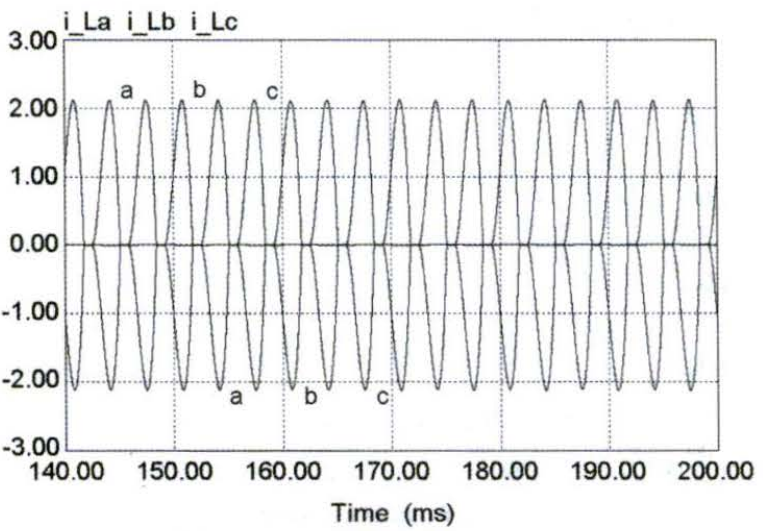

Figure 5a: The three-phase load currents (pu) for a three-phase harmonic voltage source.

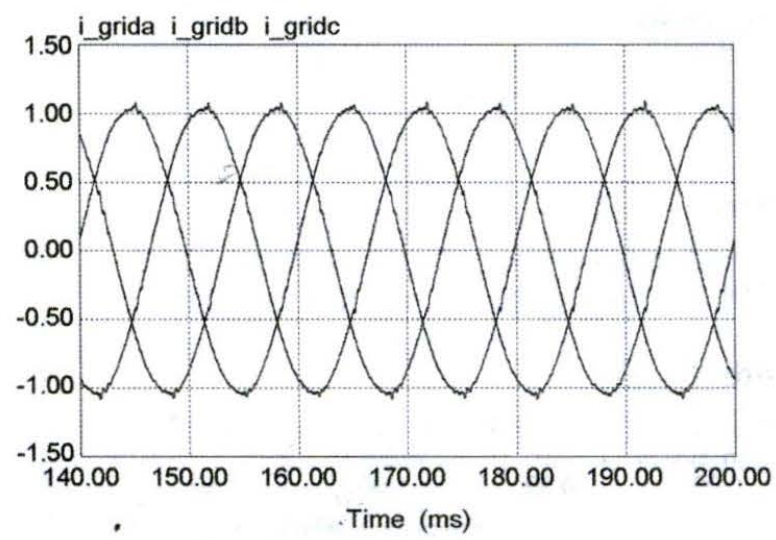

Figure 5b: The three-phase grid currents (pu) after compensation.

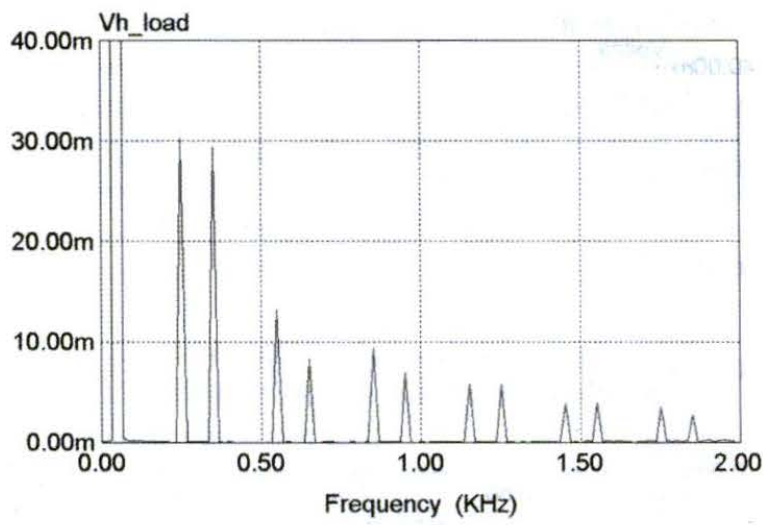

Figure 6a: Harmonic spectrum of load harmonic voltage (peak value - pu).

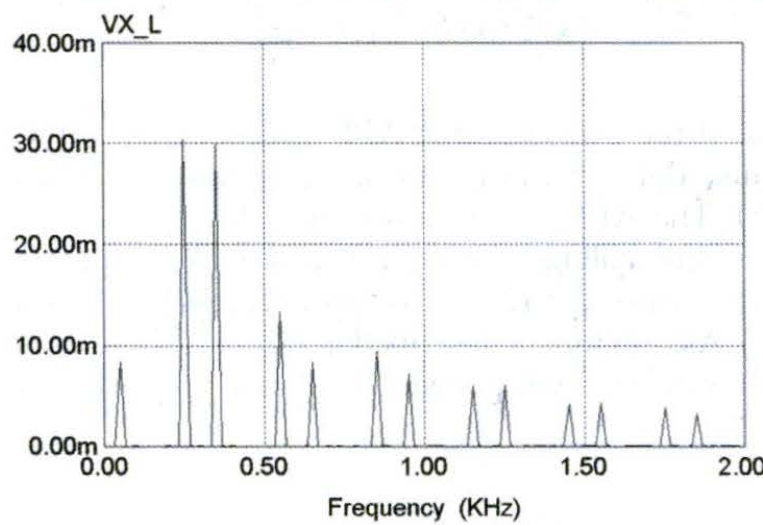

Figure 6b: Harmonic spectrum of voltage across $L_{L}$ (peak value - pu). 


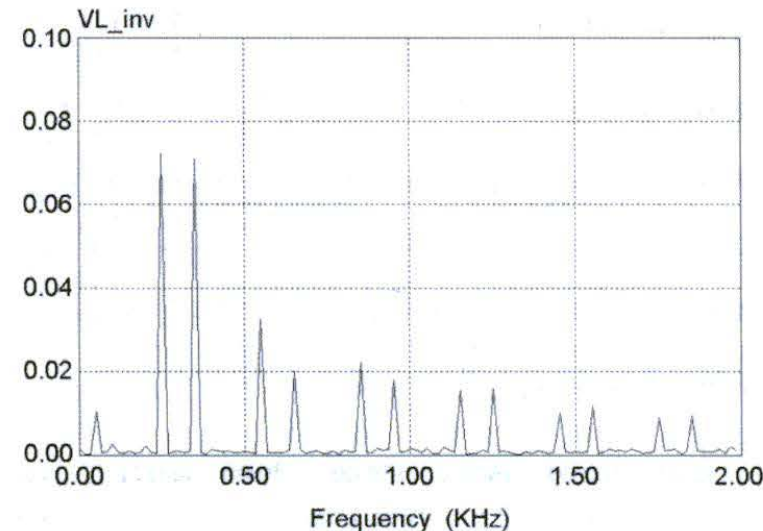

Figure 6c: Harmonic spectrum of voltage across $L_{i n v}$ (peak value - pu).

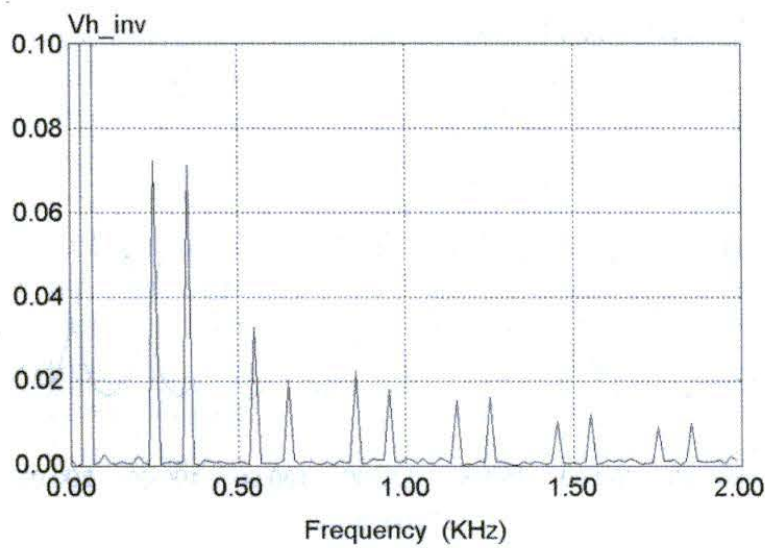

Figure 6d: Harmonic spectrum of CC-VSI output voltage (peak value - pu).

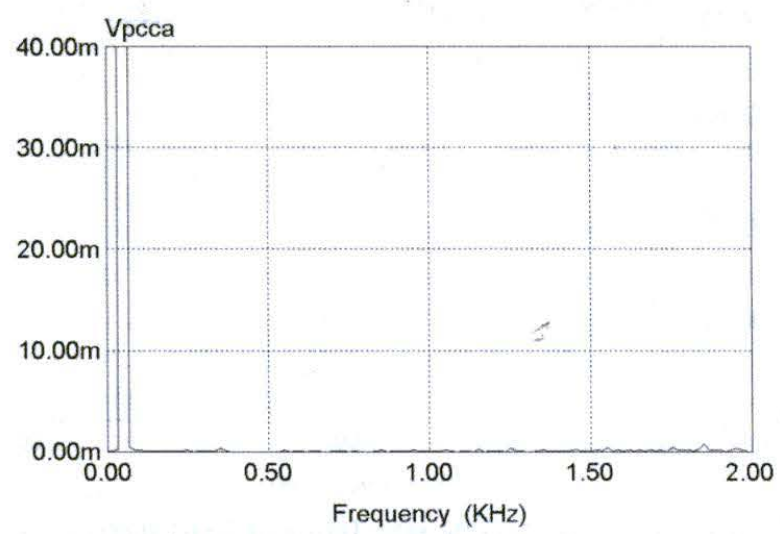

Figure 6e: Harmonic spectrum of voltage at PCC (peak value - pu).

The three-phase shunt APF successfully forces sinusoidal current from the grid, as shown in Figure 5(b). The APF combined with $L_{L}$ forces the load harmonic voltage shown in Figure 6(a) (in spectral performance up to $2 \mathrm{kHz}$ ) to appear across $L_{L}$ in Figure 6(b). As previously described in figure 2 , these same harmonic voltages appear (in relative proportion to the inductances) in the inverter output voltage in Figure 6(d) and across the inverter inductance in Figure 6(c). Thus, the load harmonic voltages do not appear across $Z_{g}$, and load harmonic currents are not created through this grid impedance. Also, assuming the grid voltage harmonics are negligible, the ac grid voltage at the PCC will be sinusoidal (Figure 6(e))

It is apparent that the CC-VSI generates harmonic voltages with the same characteristics as the load harmonic voltages. Moreover, the harmonic voltage of CC-VSI yields equal-but-opposite voltage on the inverter inductance $\left(L_{i n v}\right)$ to keep harmonic voltage at the PCC close to zero. This result leads the output current of the active filter to match the harmonic components of $i_{\text {loads }}$.

\subsection{The size of a series inductance $L_{L}$}

There are several ways to determine the size of $X_{L}$ that represents $L_{L}$. As suggested by Peng, ${ }^{5}$ the minimum value of $X_{L}$ is $6 \%$. In Al-Zamil's paper, ${ }^{6}$ the size of $X_{L}$ depends on the maximum load current slope because the reactance is used specifically to reduce the current slope of harmonic current type loads. However, the practical value of $L_{L}$ should be as small as possible to minimize cost.

If the APF can directly force the grid current to be sinusoidal, the voltage at the PCC will have similar characteristics to the grid voltage with a small sinusoidal voltage appearing across the grid impedance. While the intent of the APF is to improve the grid current, it is not expected that the APF should improve the current harmonics into the load, but only supply those harmonic currents rather than have the grid supply them. Conversely, the APF also should not increase the current harmonics into the load, since that may result in greater stress on the loads: Hence a rationale choice of decoupling inductance would be to choose a value, which results in the harmonic content of the load current being largely the same as it would have been without the APF in place.

Assuming a perfect sinusoidal (harmonic free) grid voltage source, the operation of the APF should result in a harmonic free voltage at the PCC. Hence, in order to make the loads operate in the similar operating point as if they were connected directly to the grid, then the size of $X_{L}$ should be chosen close to $Z_{g} \approx X$ in per-unit value (usually the resistance of the grid impedance is very small compared to its inductance). In other words, it is suggested to select $L_{L} \approx L_{L}$, so that the characteristics of the load current would be similar after and before installing the APF. 


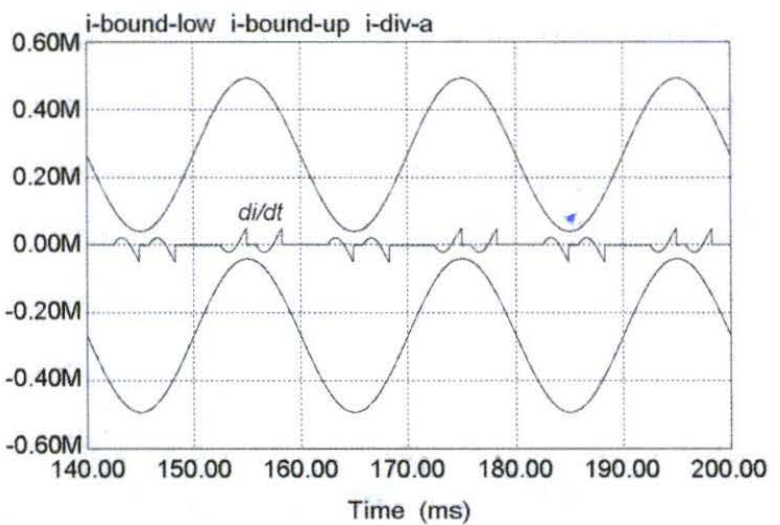

Figure 7: $\quad$ The di/dt of loads (pu) are inside the boundaries (case 1).

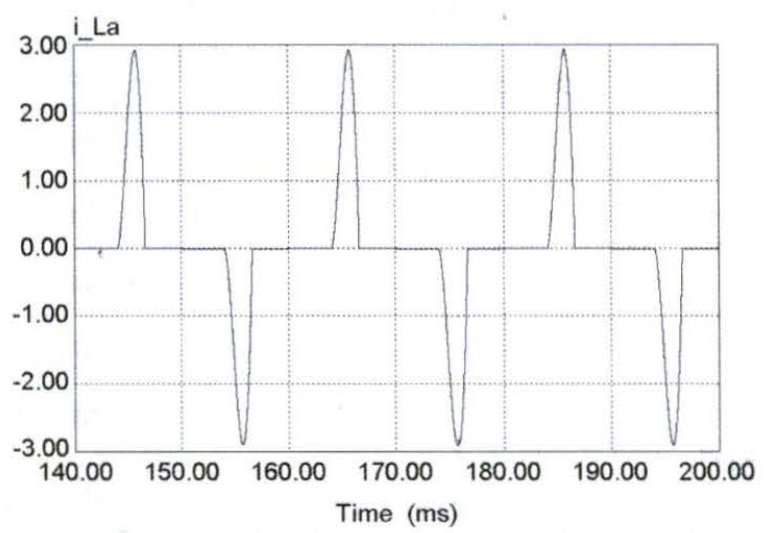

Figure 8: The load current (phase $\mathrm{A}-\mathrm{pu}$ ) for three single-phase harmonic voltage sources (case 2).

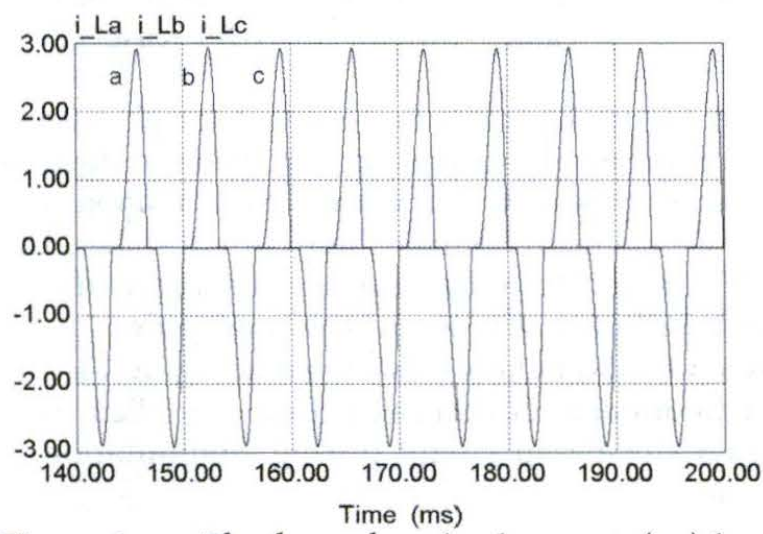

Figure 9a: The three-phase load currents $(\mathrm{pu})$ for case 2 .

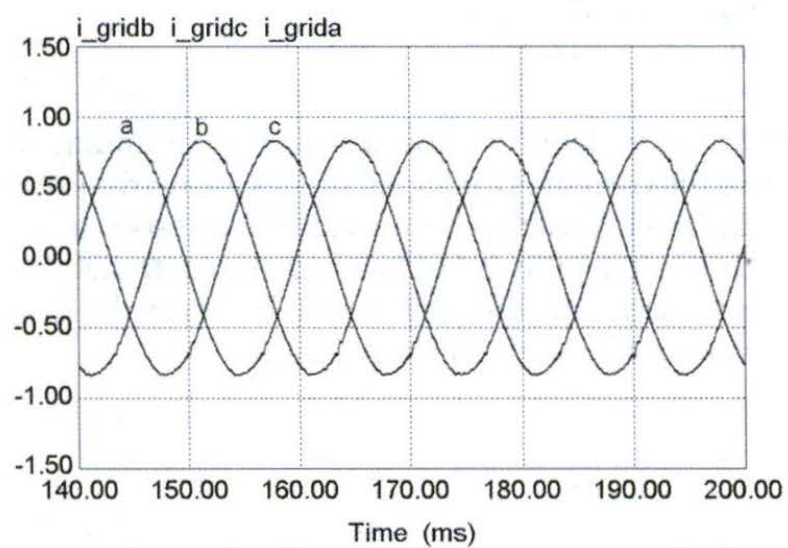

Figure 9b: The three-phase grid currents (pu) after compensation (case 2).

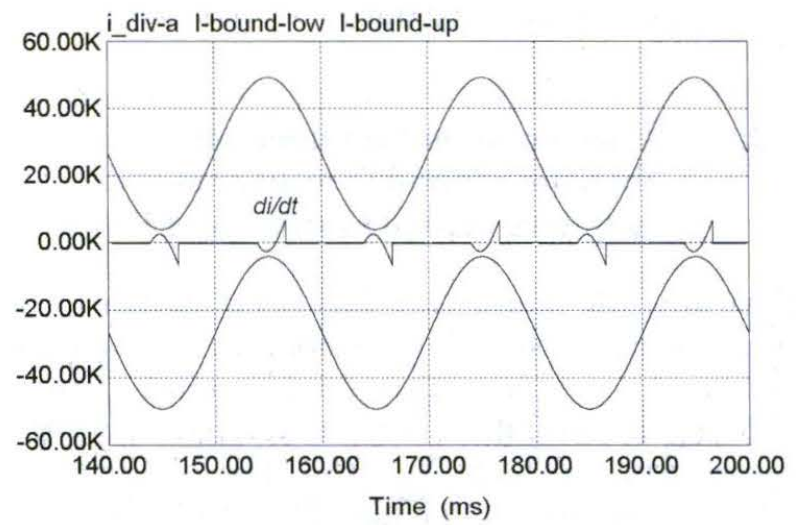

Figure 10: The di/dt of the loads (pu) are inside the boundaries (case 2).

In order to select the proper value of $L_{L^{\prime}}$ it is better to evaluate the value with three different types of loads. In this case, the circuit constants are $V_{C-d c}=3.333 \mathrm{pu}$, $X_{i n v}=1.96 \%$, and $X_{g}=0.8 \%$

\subsubsection{Compensation for a three-phase diode rectifier as harmonic voltage sources (case 1)}

From the previous section as shown in Figure 5, it is shown that for the $X_{L}=0.8 \%$, full controllability is achieved and the compensation is successful. Before compensation, the grid currents are the same as the load currents, which are 1pu per-phase. After compensation, the grid currents are sinusoidal, and the rms values are reduced to $0.74 \mathrm{pu}$. The small series inductance $L_{L^{\prime}}$ which is close to $L_{s}$ provides voltage decoupling between the load harmonic voltage and the grid. Moreover, $L_{L}$ forces the $d i / d t$ of loads inside the boundaries of controllability as shown in Figure 7.

\subsubsection{Compensation for a three single-phase diode rectifier as harmonic voltage sources (case 2)}

To show a compensation for three per-phase singlephase diode rectifiers as harmonic voltage sources $\left(\mathrm{I}_{\text {load-rms }}=1 \mathrm{pu}\right)$, a simulation was conducted using the same circuit constants, with $X_{L}=0.8 \%$. The load and grid currents can be seen in Figures 8 and 9 .

From Figure 9, it is shown that with $X_{L}=0.8 \%$, full controllability is achieved. The compensation is successful and the grid currents are sinusoidal. The added series inductance $L_{L}$ provides voltage decoupling between the load harmonic voltage and the grid. Moreover, for only $L_{L}=L_{g}$ (neglecting the resistance of the line impedance), the requirement of controllability is satisfied, and the $d i_{\text {loads }} / d t$ is inside the envelope of the boundaries of controllability, as shown in Figure 10. $L_{L}$ could be smaller as long as sufficient voltage decoupling is provided and the di/dt of the loads is still inside the 
boundaries of controllability.

\subsubsection{Compensation for a three-phase thyristor controlled rectifier as harmonic current sources (case 3)}

Basically, the shunt APF has been shown to be effective in compensating harmonic current sources. To show a compensation for harmonic current sources, a simulation was conducted using the same circuit constants. $X_{L}=0.8 \%$. The load and grid currents can be seen in Figure 11 and 12. The firing angle for the thyristor control circuit is chosen at $60^{\circ}$, and $\mathrm{I}_{\text {load-rms }}=1 \mathrm{pu}$

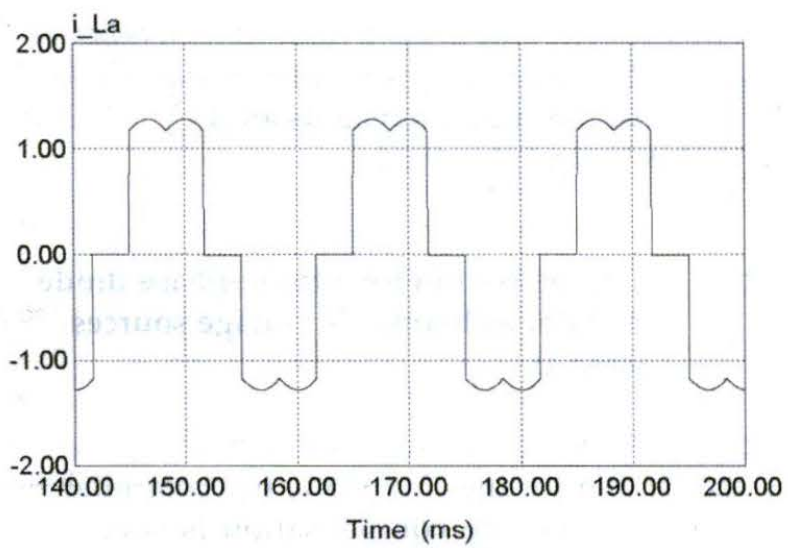

Figure 11: The load current (phase A - pu) for a three-phase harmonic current source.

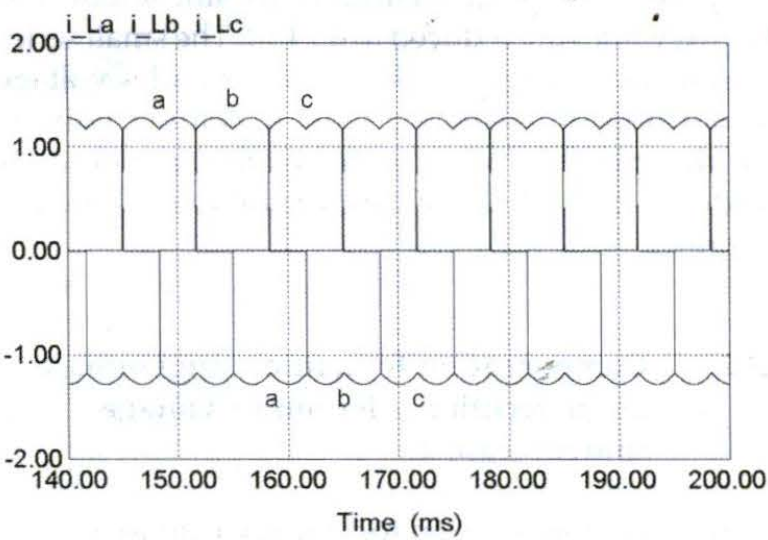

Figure 12a: The three-phase load currents (pu) for case 3 .

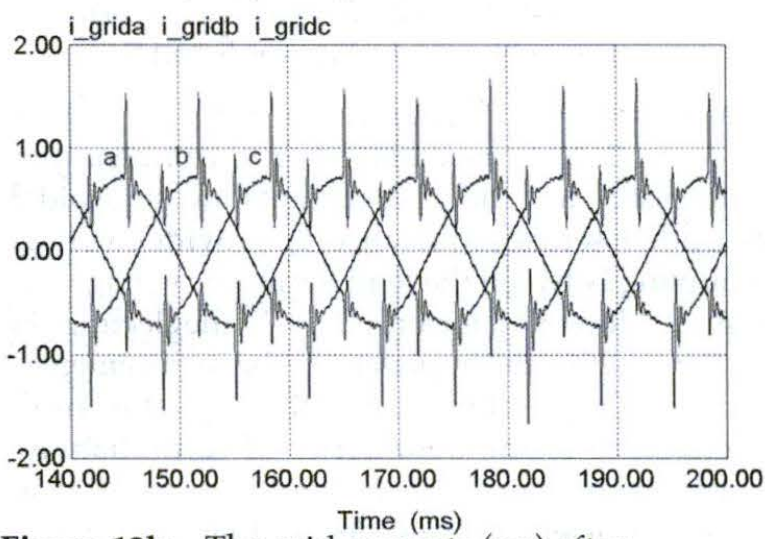

Figure 12b: The grid currents (pu) after compensation, for $X_{L}=0.8 \%$ (case 3 ).

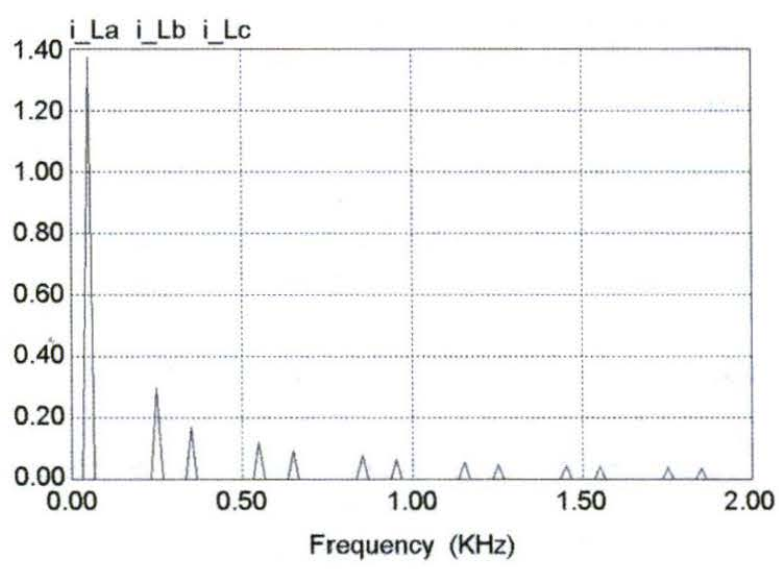

Figure 12c: Spectrum of the load currents (peak value - pu) for case 3 .

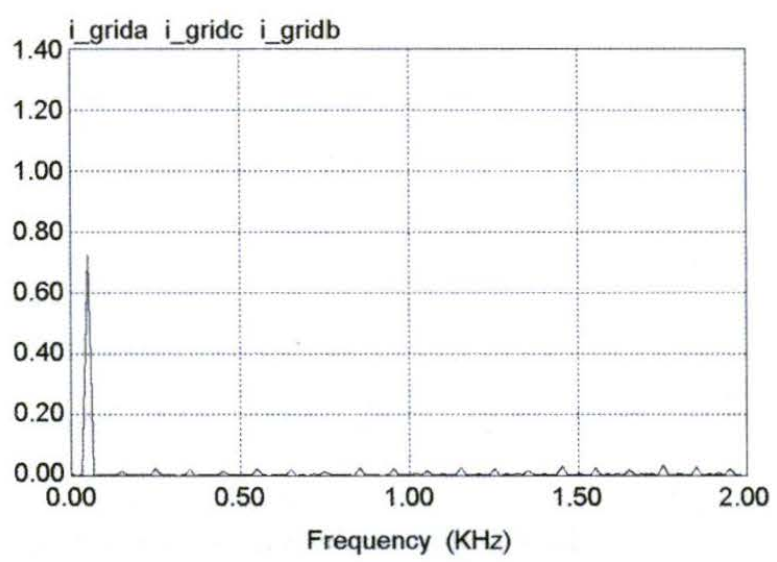

Figure 12d: Spectrum of the grid currents (peak value - pu), for $X_{L}=0.8 \%$ (case 3 ).

From Figure 12, it can be seen that for $X_{L}=0.8 \%$, the compensation creates current spikes in the grid currents at the instant of current commutation. The APF is unable to eliminate these current spikes. The $\mathrm{APF}$ attempts to compensate for the larger current error, but at that moment the maximum $d_{\text {iloads }} / d t$ exceed the boundaries, as shown in Figure 13. The maximum di/dt of non-linear loads supplied from a thyristor-based circuit during commutation is given as: ${ }^{7}$

$\frac{d i_{\text {loads }}}{d t}=\frac{\sqrt{2} \sqrt{3} v_{P C C}}{2 L_{L}}$

Strict controllability is lost during the commutation since the current error signal moves away from zero regardless of switch position. However, as soon as the commutation process has finished, the controllability is returned, and the APF is able to force the grid current to follow the reference value. 


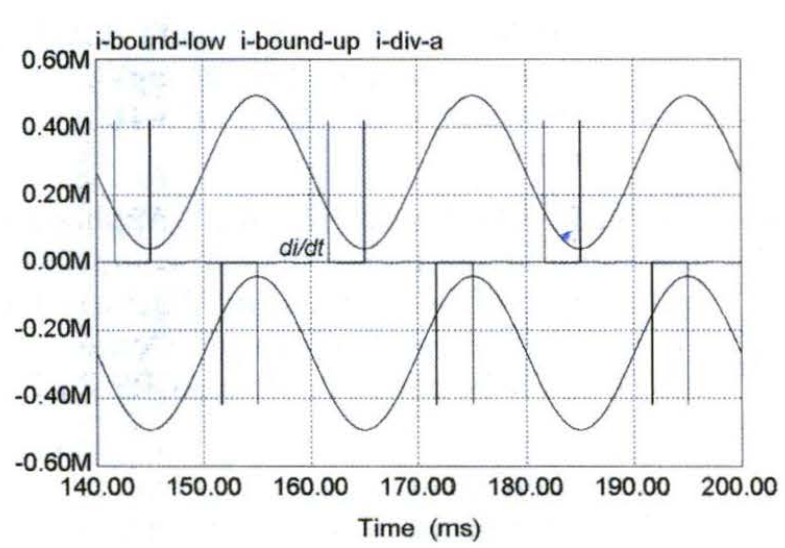

Figure 13: The $d i / d t$ of the loads (pu) exceeds the boundaries for $X_{L}=0.8 \%$ (case 3 ).

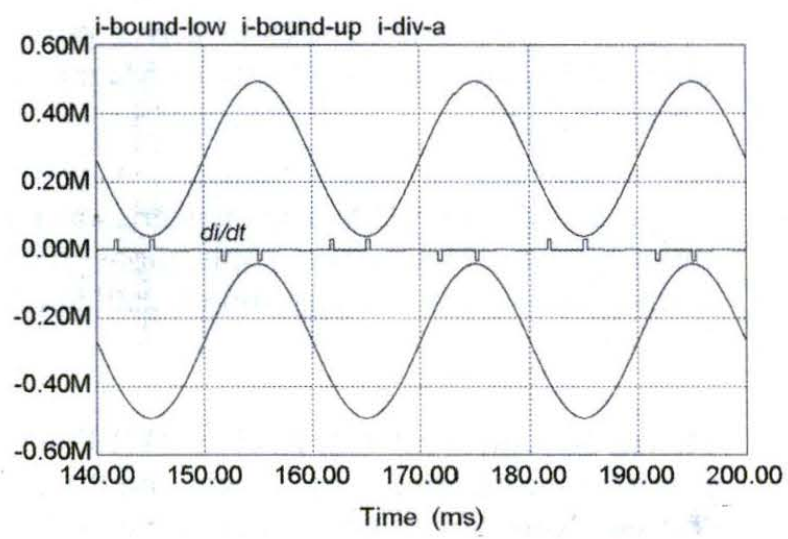

Figure 14: The di/dt of the loads (pu) are inside the boundaries for $X_{L}=11.13 \%$ (case 3 ).

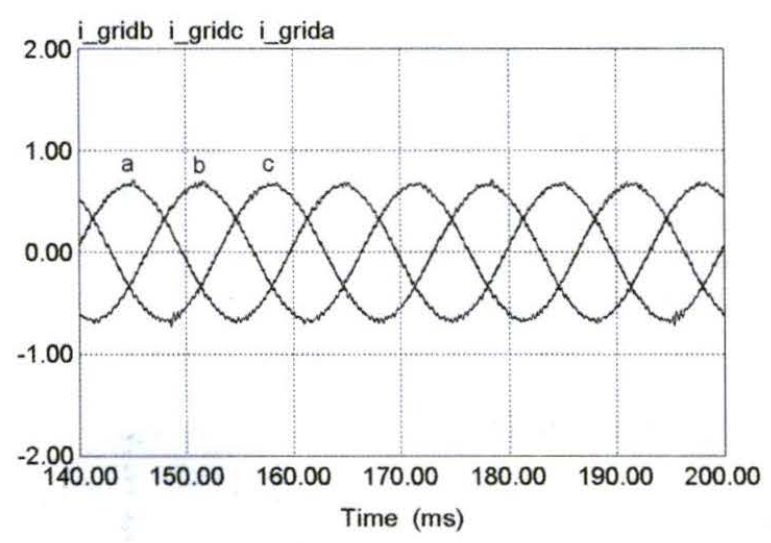

Figure 15: The grid currents $(\mathrm{pu})$ after compensation for $X_{L}=11.13 \%$ (case 3).

To reduce the spikes, either $L_{L}$ must be increased in order to reduce the $d i / d t$ of the loads, or the boundaries of controllability of the inverter must be increased. The latter is undesirable due to device limitations. For $d i_{A P F} / d t$ greater than $d i / d t$ of the loads, from (3) and (4), the value of $L_{L}$ can be expressed as:

$$
L_{\text {inv }}<L_{L}(0.4 m-1.155)
$$

where $\mathrm{m}=V_{C} / V_{P C C-r m s}$. For $\mathrm{V}_{\text {PCC-rms }}=1 \mathrm{pu}$ and $V_{C}=$ 3.333pu, $L_{L}$ must be about six times larger than $L_{i n v}$. By increasing $X_{L}$ to $11.13 \%$, with $X_{i n v}=1.96 \%$, the $d i / d t$ of the load is between the upper and lower envelope of the controllable region (Figure 14). Then, full controllability is achieved, the compensation is successful, and the spikes of the grid currents are significantly attenuated (Figure 15).

Undeniably, for $X_{L}=0.8 \%$, it can be seen from the current spectrum (up to $2 \mathrm{kHz}$ ) in Figure 12d that the low order harmonics are reduced significantly. However, the THD of the grid currents is relatively high $(17.6 \%)$ due to the spikes. By increasing $L_{L}$ to a higher value, the $d i / d t$ of the loads is reduced. Consequently, controllability is improved, the spikes are attenuated, and the THD is reduced. For this case, the relationship between $L_{L}$ (relative to $L_{i n v}$ ) and the THD of the grid currents is shown in Figure 16.

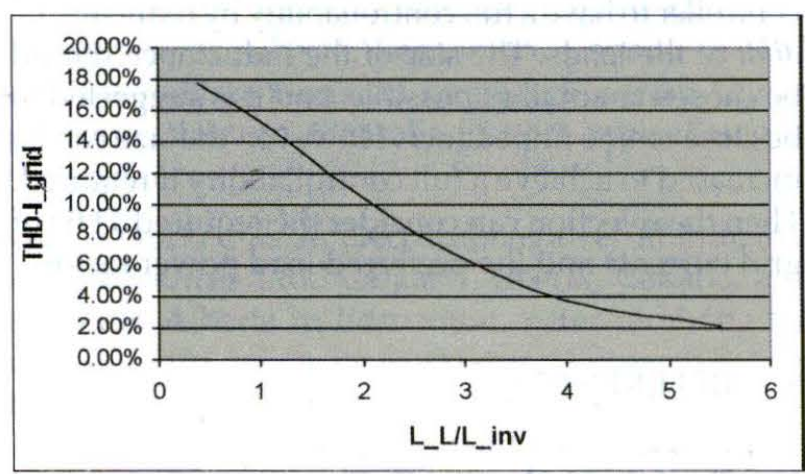

Figure 16: THD- $\mathrm{I}_{\text {grid }}$, vs a series inductance $L_{L}$ (case 3).

\subsection{A series inductance $L_{L}$ and power factor of the loads.}

As mentioned above, $X_{L}$ should be selected close to $X_{s}$ in per-unit value so that the load operates at a similar point before and after installing the APF. In other words, the existence of the APF and a series inductance $L_{L}$ would not change the characteristics of the loads. A measure of this load characteristic is the true power factor. In Table 1, for voltage-harmonic producing loads (diode-capacitor rectifiers), it can be seen that the operation of the APF with increasing series inductance results in an increasing improvement in the load power factor.

Table 1: $\quad$ The load power factor due to $L_{L}$

\begin{tabular}{|l|l|l|l|l|l|l|}
\hline & $\begin{array}{l}\text { With- } \\
\text { out } \\
\text { APF }\end{array}$ & 0.8 & 1.96 & 5 & 7.85 & 11.13 \\
\cline { 3 - 7 } & 0.602 & 0.603 & 0.664 & 0.722 & 0.748 & 0.766 \\
\hline $\begin{array}{l}\text { 1-ph Diode } \\
\text { rectifier }\end{array}$ & & & & & & \\
\hline $\begin{array}{l}\text { 3-ph Diode } \\
\text { rectifier }\end{array}$ & 0.711 & 0.711 & 0.795 & 0.906 & 0.923 & 0.929 \\
\hline $\begin{array}{l}\text { 3-ph Thyris- } \\
\text { tor control- } \\
\text { led rectifier }\end{array}$ & 0.474 & 0.477 & 0.475 & 0.469 & 0.464 & 0.458 \\
\hline
\end{tabular}


For the current-harmonic producing load (threephase controlled rectifier with dc side inductance), the power factor is relatively constant with increasing series inductance. If the size of $X_{L}$ is selected close to $X_{q^{\prime}}$ the power factor of both voltage-harmonic producing and current-harmonic producing loads is maintained unchanged after the installation of the APF.

\section{CONCLUSION}

The series inductance $L_{L}$ is an important component that supports the APF to compensate harmonics. The main role is to handle the problem of harmonic voltage sources. Moreover, it helps the current controller to have a full controllability by reducing the $d i / d t$ of the loads. The size of the inductance should be chosen as small as possible, and it is suggested to be close to line impedance. However, the size can be increased to achieve a full controllability if required. Then the selection can consider the required THD of grid currents and the preferred load power factor.

\section{REFERENCES}

1. Singh B, Al-Haddad K, Chandra A. A review of active filters for power quality improvement. IEEE Transactions on Industrial Electronics, 1999;46(5):960-971.
2. El-Habrouk M, Darwish MK, Mehta P. Active power filters: a review. IEE Proceedings Electric Power Applications, 2000;147(5):403-413.

3. Tumbelaka HH, Borle LJ, Nayar CV. Application of a shunt active power filter to compensate multiple non-linear loads. In: Australasian Universities Power Engineering Conference (AUPEC); Melbourne, Australia: ACPE; 2002.

4. Borle L. Zero average current error control methods for bidirectional ac-dc converters. Western Australia: Curtin University of Technology; 1999. PhD Thesis

5. Peng FZ. Application issues of active power filters. IEEE Industry Applications Magazine, 1998;4(5):21-30.

6. Al-Zamil AM, Torrey DA. A passive series, active shunt filter for high power applications. IEEE Transactions on Power Electronics, 2001;16(1): 101-109.

7. Mohan N, Undeland TM, Robbins WP. Power electronics: converter, applications, and design. 2nd ed. New York: John Wiley \& Sons, Inc; 1995. 

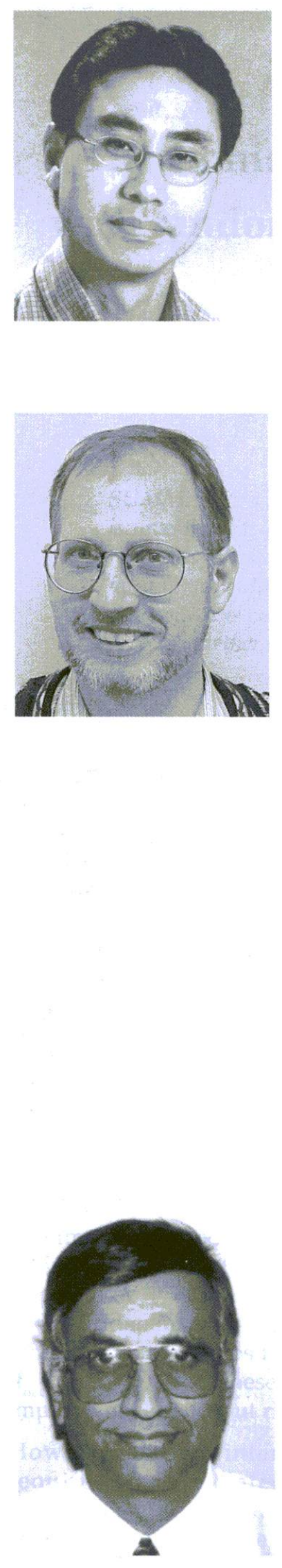

\section{HANNY H TUMBELAKA}

Hanny H Tumbelaka obtained the Bachelor of Electrical Engineering degree from Petra Christian University, Indonesia, in 1988, and the Master of Science degree in Electric Power Engineering from Rensselaer Polytechnic Institute, New York, USA in 1993. In 1989, he joined Petra Christian University, Indonesia as a Lecturer. Since 2002, Hanny has been a PhD student in Electrical and Computer Engineering, Curtin University of Technology, Western Australia.

\section{LAWRENCE JOSEPH BORLE}

Lawrence Joseph Borle received his BSc and MSc degrees in Electrical Engineering from the University of Alberta, Edmonton, Canada in 1982 and 1991 respectively, and his $\mathrm{PhD}$ in Electrical Engineering from Curtin University of Technology, Perth, Western Australia in 1999, specializing in current control in power electronics.

From 1982 to 1988, Lawrence worked as an electrical engineer in industry, first with Chevron Canada Resources Ltd., Calgary, Alberta, Canada, and then with Nova Corporation of Alberta in Edmonton. After receiving his MSc, Lawrence travelled to Australia, where he worked as a Research Fellow for two years on current controlled, grid connected inverters in joint venture projects between Curtin University of Technology and Advanced Energy Systems Pty Ltd (AES), both in Perth, Western Australia. From 1994 to 2000, Lawrence worked in research and engineering functions on power converters for renewable energy applications with AES. In 2000, Lawrence joined Curtin University of Technology as a Lecturer where he taught mainly power electronics. In 2002, Lawrence joined the University of Western Australia as a Senior Lecturer where he is teaching in power electronics, electric machines, and high voltage power conversion (HVDC \& FACTS). Lawrence's research interests include the application of power electronics to solve problems related to sustainable energy, power quality, and electric vehicles.

Lawrence is a member of the IEEE, is a Chartered Professional Engineer in Engineers Australia and is registered on the National Professional Engineers Register (NPER).

\section{CHEMMANGOT V NAYAR}

Chemmangot V Nayar (SM) obtained the Bachelor of Electrical Engineering degree from the University of Kerala, India, in 1969, the Master of Technology degree in electronics from the Indian Institute of Technology, Kanpur, in 1976, and the $\mathrm{PhD}$ degree in electrical engineering, specializing in wind electrical power generation, from the University of Western Australia in 1985.

Prior to joining the School of Electrical \& Computer Engineering at the Curtin University of Technology in Perth in 1986, he held academic and industry appointments in India, Singapore, and Australia. He holds a personal chair in electrical engineering and was also the Director of the Centre for Renewable Energy and Sustainable Technologies (CRESTA) at Curtin University of Technology. He has a large number of publications in international journals and conference proceedings.

Prof Nayar is a Chartered Engineer and Corporate Member of IEE, and Chartered Professional Engineer and Fellow of Engineer Australia and Senior Member of IEEE. 